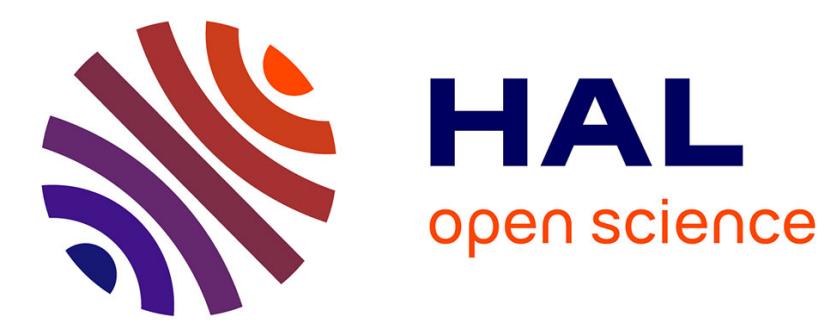

\title{
Use of ENVISAT/ASAR wide-swath data for timely rice fields mapping in the Mekong River Delta
}

\author{
Alexandre Bouvet, Thuy Le Toan
}

\section{To cite this version:}

Alexandre Bouvet, Thuy Le Toan. Use of ENVISAT/ASAR wide-swath data for timely rice fields mapping in the Mekong River Delta. Remote Sensing of Environment, 2011, 115 (4), pp.1090-1101. 10.1016/j.rse.2010.12.014 . hal-00563142

\section{HAL Id: hal-00563142 \\ https://hal.science/hal-00563142}

Submitted on 4 Feb 2011

HAL is a multi-disciplinary open access archive for the deposit and dissemination of scientific research documents, whether they are published or not. The documents may come from teaching and research institutions in France or abroad, or from public or private research centers.
L'archive ouverte pluridisciplinaire HAL, est destinée au dépôt et à la diffusion de documents scientifiques de niveau recherche, publiés ou non, émanant des établissements d'enseignement et de recherche français ou étrangers, des laboratoires publics ou privés. 
11 Because of the importance of rice for the global food security and because of the role of

12 inundated paddy fields in greenhouse gases emissions, monitoring the rice production world-

13 wide has become a challenging issue for the coming years. Local rice mapping methods have

14 been developed previously in many studies by using the temporal change of the backscatter from

15 C-band synthetic aperture radar (SAR) co-polarized data. The studies indicated in particular the

16 need of a high observation frequency. In the past, the operational use of these methods has been

17 limited by the small coverage and the poor acquisition frequency of the available data (ERS-1/2,

18 Radarsat-1). In this paper, the method is adapted for the first time to map rice at large scale, by

19 using wide-swath images of the Advanced SAR (ASAR) instrument onboard ENVISAT. To

20 increase the observation frequency, data from different satellite tracks are combined. The

21 detection of rice fields is achieved by exploiting the high backscatter increase at the beginning of

22 the growing cycle, which allows the production of rice maps early in the season (in the first 50

23 days). The method is tested in the Mekong delta in Vietnam. The mapping results are compared 
24 to existing rice maps in the An Giang province, with a good agreement (higher than $81 \%$ ). The

25 rice planted areas are retrieved from the maps and successfully validated with the official

26 statistics available at each province $\left(\mathrm{R}^{2}=0.92\right)$. These results show that the method is useful for

27 large scale early mapping of rice areas, using current and future $\mathrm{C}$ band wide-swath SAR data.

\section{I. INTRODUCTION}

31 Rice is the staple food for more than half of humanity. Global rice production has increased

32 continuously in the last half-century, since the Green Revolution. In the same period, the use of

33 chemical inputs, the introduction of modern high-yielding varieties with short growing cycles,

34 and the increased access to machinery and irrigation systems have led to a linear growth of the

35 crop yields ( +0.05 ton/ha/year) according to the FAO (Food and Agriculture Organization of the

36 United Nations 2009) as well as to an increase of the number of crops per year. This higher

37 cropping intensity (from single to double or triple crop) together with the conversion of non-

38 arable land to arable land have resulted in a drastic increase of rice harvested areas in the $60 \mathrm{~s}$

39 and $70 \mathrm{~s}(+1.4 \mathrm{Mha} / \mathrm{year})$ which slowed down in the $80 \mathrm{~s}$ and $90 \mathrm{~s}(+0.46 \mathrm{Mha} / \mathrm{year})$ and has tended

40 to stabilize over the last ten years as a result of approaching the limits of land use and of

41 cropping intensity, however with a large inter-annual variability due to climatic conditions and

42 socio-economic factors. As both the increase in yield and in planted areas will be facing

43 limitations in the next decades, it is unlikely that rice production can keep increasing at the same

44 rate. Meanwhile, world population, and therefore demand for food, has increased linearly over

45 the last fifty years ( $+80 \mathrm{M} /$ year), and is projected to keep growing until around 2050 up to 9

46 billion inhabitants (United Nations Department of Economic and Social Affairs, Population 
47 Division 2004). This conjuncture is prone to create tensions in food markets that could lead to

48 world food price crises - as in April 2008 when the price of rice has more than doubled in only

49 seven months - and eventually to famines. In this context of price instability and threatened food

50 security, tools to monitor rice production in real-time are highly needed by governments, traders

51 and decision makers.

52 Moreover, rice agriculture is strongly involved in various environmental aspects, from water

53 management to climate change due to the high emissions of methane. For this reason, a longer-

54 term inter-annual monitoring is also required in order to study the impact of the changes in rice

55 areas and in cultural practices that are likely to occur in the next years to face the economic and

56 environmental context.

57 Satellite remote sensing data offer a unique possibility to provide frequent and regional to 58 global-scale observations of the Earth over a long period (the lifespan of a satellite is around 10 59 years, and satellites are launched regularly to provide continuity in the data).

61 Optical sensors are seriously limited by frequent cloud cover in tropical and sub-tropical areas 62 where rice is grown in majority. A study combining agricultural census data and a large dataset 63 of Landsat TM imagery allowed producing maps of the distribution of rice agriculture in China 64 at a $0.5^{\circ}$ spatial resolution (Frolking et al. 2002). However, to achieve the coverage of such a 65 large area with high-resolution (30m) optical images, a consequent amount of data (520 scenes) 66 had to be collected over a period of two years, which makes the method unsuitable for the 67 production of timely statistics or yearly results. Because of the need of a high temporal 68 observation frequency to get enough cloud-free images, a frequent global coverage can be 69 ensured only through the use of medium resolution (around $250 \mathrm{~m}-1 \mathrm{~km}$ ) sensors, such as the 
MODerate resolution Imaging Spectrometer (MODIS), VEGETATION, or the MEdium

71 Resolution Imaging Spectroradiometer (MERIS). The joint analysis of time-series of vegetation

72 and water indices derived from these sensors, such as the Normalized Difference Vegetation

73 Index (NDVI), the Enhanced Vegetation Index (EVI), or the Normalized Difference Water

74 Index (NDWI), also known as the Land Surface Water Index (LSWI), exhibits a specific

75 temporal behaviour during flooding of rice paddies and transplanting of rice plants. This feature

76 has been exploited to map the spatial distribution of rice agriculture at large scales in China

77 using VEGETATION (Xiao et al. 2002a; Xiao et al. 2002b) and MODIS (Xiao et al. 2005), and

78 in South and South-East Asia using MODIS (Xiao et al. 2006). Although these methods have

79 produced very valuable outputs, none of them allows the retrieval of planted areas without the

80 use of ancillary data. Indeed, because of the large number of mixed pixels at such spatial

81 resolutions, the fractional cover of rice in each pixel classified as rice had to be estimated

82 through the use of high-resolution Landsat TM imagery (Xiao et al. 2002b; Xiao et al. 2005).

83 Also, in (Xiao et al. 2006), the cropping intensity had to be derived from national agricultural

84 statistics datasets, and the rice distribution in the Mekong River Delta was not properly reported

85 according to the authors, probably because the flood pattern misleads the rice detection

86 algorithm. The spatio-temporal distribution of rice phenology in the Mekong River Delta has

87 been accurately estimated by an harmonic analysis of EVI time profiles from MODIS

88 (Sakamoto et al. 2006). However, this method is not able to discriminate rice from other crops or

89 vegetation types, and a prior identification of rice fields - e.g. by existing databases - is therefore

90 needed.

91 Radar imaging systems, contrarily to optical sensors, have an all-weather capacity. The radar

92 data are also well adapted to distinguish rice from other land cover types because of the specific 
93 response of the radar backscattering of inundated vegetation. The interaction between a radar

94 electromagnetic wave and vegetation involves mainly three mechanisms: the volume scattering,

95 the scattering from the ground attenuated by the vegetation canopy, and the multiple scattering

96 between the volume and the ground. The last term brings a negligible contribution compared to

97 the two others in the usual case of vegetation growing over non-flooded soils. However, in the

98 case of flooded fields such as rice paddies, this term becomes dominant when the plants develop

99 because of the double-bounce between the plant stems (which are the dominant scatterers in the

100 volume) and the water surface. This has been demonstrated by theoretical models for the case of

101 C-band co-polarized (HH or VV) backscatter at 23 incidence angle (Le Toan et al. 1997; Wang

102 et al. 2005). This volume-ground interaction (double-bounce) is responsible for the first of the

103 two main properties of the rice backscatter: the backscattering intensity at polarizations $\mathrm{HH}$ and

104 VV show a significant increase during the vegetative phase, right after the low values of the

105 flooding stage, and then decrease slightly during the reproductive phase until harvest. This

106 backscatter increase in rice fields was generally observed from ERS, RADARSAT-1 or ASAR

107 to be superior to $8 \mathrm{~dB}$, and sometimes much more (Chakraborty et al. 2005; Chen et al. 2007;

108 Kurosu et al. 1995; Shao et al. 2001). Scatterometer measurements on an experimental paddy

109 field in Japan have shown that this high backscatter increase is observed not only at C-band but

110 also at X-band and L-band (Inoue et al. 2002). For L-band however, other studies demonstrated

111 that in the case of mechanically planted fields, this increase is smaller (3-4 dB) except in specific

112 configurations of the plant rows (orientation and spacing) where resonant scattering leads to

113 extreme backscatter increases of more than $20 \mathrm{~dB}$ (Rosenqvist 1999). This dependence on the

114 plant row configuration limits the usefulness of L-band data for operational applications at wide-

115 scale. 
116 The vertical structure of the rice plants is responsible for the second property of the rice

117 backscatter: the vertically polarized wave is more attenuated than the horizontally polarized

118 wave, and for that reason the ratio of the HH and VV backscatter intensities is higher than that

119 of most other land cover classes, reaching values around $6-7 \mathrm{~dB}$ according to a joint analysis of

120 ERS and RADARSAT-1 data (Le Toan et al. 1997; Ribbes and Le Toan 1999) and to the

121 modelling of C-band HH and VV (Le Toan et al. 1997; Wang et al. 2005). The same is observed

122 at X-band (Le Toan et al. 1989).

123 The rice fields mapping methods based on SAR data that have been developed so far mainly rely

124 on these two properties of rice fields. The first property (high backscatter increase during rice

125 growing season) has been exploited in classification algorithms using the temporal change of co-

126 polarized backscatter as a classification feature, mostly at C-band, in various Asian countries

127 (Chen and McNairn 2006; Le Toan et al. 1997; Liew et al. 1998; Ribbes and Le Toan 1999).

128 The second property (high $\mathrm{HH} / \mathrm{VV}$ polarization ratio) has led to the development of methods

129 using this polarization ratio as a classification feature, at C-band in Vietnam (Bouvet et al. 2009)

130 and at X-band in Spain (Lopez-Sanchez et al. 2010). All these rice mapping schemes have

131 proven effective but have been applied only at local scales, with high resolution (less than $50 \mathrm{~m}$ )

132 data. The use of these methods and data to map rice on larger areas (regional to continental

133 scales) would require the acquisition and processing of a dissuasive amount of high resolution

134 data. The existence of wide-swath sensors in current (ASAR, RADARSAT-2, PALSAR) or

135 future (Sentinel-1, RISAT-1) systems opens the way to the adaptation of these methods to

136 medium-resolution $(50-100 \mathrm{~m})$ data for the mapping of rice areas at large scale. However, no

137 satellite wide-swath data with dual-polarization HH and VV capability is available so far, so

138 only the methods based on backscatter temporal change can be considered. 
139 The present study aims at developing an operational method for the early assessment of rice

140 planted areas using medium-resolution wide-swath single-polarization SAR imagery, by

141 exploiting the outstanding temporal behaviour of rice backscattering. Because of the limitations

142 of L-band in mechanically planted fields and because of the absence of wide-swath sensors

143 operating at X-band, we choose to use C-band data. Section II describes the test site and the data

144 used in the study. The mapping method is developed in Section III. Section IV presents the 145 mapping results and their validation.

\section{II. SITE AND DATA}

149 A. Site description

150 The study site is the Mekong Delta, the major rice-producing area in Vietnam. It produces more 151 than half of the rice in Vietnam, thus accounting for around 3\% of the world production.

152 The Mekong Delta is a region constituted by 13 provinces in the southern tip of the country, 153 covering around $40000 \mathrm{~km}^{2}$ (275km from North to South, $260 \mathrm{~km}$ from West to East), where the 154 Mekong River approaches and empties into the South China sea through a network of nine main 155 distributaries. The topography is very flat, with most of the land below $5 \mathrm{~m}$. Figure 1 presents the 156 locations and names of the 13 provinces and the topography of the area from the Shuttle Radar 157 Topography Mission (SRTM) Digital Elevation Model (DEM). The climate is tropical $\left(8.5^{\circ} \mathrm{N}-\right.$ $15811^{\circ} \mathrm{N}$ in latitude), with the wet season starting in May and lasting until October-November, and 159 the dry season from December to April. Seasonal floods occur in a large part of the area, starting 160 in August in the upper Delta, then spreading to the lower Delta, peaking in September-October 161 and lasting until the beginning of December. The floods bring large amounts of silt that 
162 contribute to the fertilization of the soil. The land is dedicated mostly to agriculture $(63 \%)$, 163 aquaculture (17.7\%) and forestry (8.9\%) (General Statistics Office of Vietnam 2006), with the 164 agricultural land comprising predominantly rice paddies (76\%), as well as orchards, sugarcane 165 and annual crops (General Statistics Office of Vietnam 2009). The delta is therefore a rural, but 166 very densely populated area, with 17.7 million inhabitants.



169 Figure 1. Map of the 13 provinces in the Mekong River Delta and topography from SRTM.

171 The rice cultivation pattern is quite complex. Originally, floating rice paddies were cultivated 172 and, being dependent on rainfall and seasonal floods, only one crop of rice was harvested every

173 year, during the wet season. However, in the last decades, the introduction of modern varieties, 174 with higher yields and a shorter growth cycle, and technical components such as chemical 
175 fertilizers, pesticides, machinery and low-lift pumps together with the development of canal 176 networks have led to the intensification of paddy agriculture, allowing to grow two or sometimes

177 three crops of rice per year (Tanaka 1995).

178 The land can be divided roughly into two ecological types: inland areas and coastal areas. Inland 179 areas are covered with a dense irrigation network and benefit from a fertile soil thanks to the 180 sediments brought by the floods, which allow double or triple-cropping of rice. They are formed 181 by inland provinces: An Giang, Đồng Tháp, Cần Thơ, Hậu Giang, Vĩnh Long, the western part 182 of Tiền Giang, and Long An. Coastal areas are prone to salt intrusion in the dry season which 183 limits the soil fertility. The major cropping patterns are therefore single rice with shrimp farming 184 or double rice. This concerns part or all of the coastal provinces: Kiên Giang, Cà Mau, Bạc Liêu, 185 Sóc Trăng, Trà Vinh and Bến Tre.

187 In inland areas, one crop of rice is grown during the dry season. This "Winter-Spring" rice 188 (locally called "Đông Xuân") is planted in November-December and harvested between 189 February and April. In the wet season, farmers grow one or two crops of rice. The "Summer190 Autumn" crop (locally named "Hè Thu") is planted in April-early June and harvested in July191 early August. When the fields are protected from seasonal floods (dykes have been built after the 1922000 record floods), a second wet-season crop is grown. This "Autumn-Winter" rice (locally 193 named "Thu Đông") is transplanted in August and harvested in November-December.

194 In coastal areas where saline intrusion limit the number of rice crops per year, one Summer195 Autumn rice is grown and a second crop in the "Main wet season" (locally called "Mùa"), which 196 is planted from July to August and harvested from November to February, i.e. with a variable 197 calendar between early, medium and late fields. 
198 Table 1 sums up the information related to these seasons. Rice seasons are numbered according

199 to their order of occurrence in the civil year.

201 Table 1. Rice agricultural seasons in the Mekong Delta River

\begin{tabular}{|c|c|c|c|c|c|}
\hline Season & English name & Vietnamese & Planting & Harvest & Distribution \\
\hline $\mathbf{1}$ & Winter-Spring & Đông Xuân & Nov-Dec & Feb-Apr & inland \\
\hline $\mathbf{2}$ & Summer-Autumn & Hè Thu & Apr-Jun & Jul-Aug & inland and coastal \\
\hline 3a & Autumn-Winter & Thu Đông & Aug & Nov-Dec & inland \\
\hline $\mathbf{3 b}$ & Main wet season & Mùa & Jul-Aug & Nov-Feb & coastal \\
\hline
\end{tabular}

\section{B. Statistical data}

205 The mapping methods developed in this paper will be validated through the comparison of the

206 planted areas retrieved from the remote sensing methods to the planted areas reported in the

207 official national statistical data.

208 The statistical system in Vietnam is centralized. Statistical data are collected first at the

209 commune level, and then aggregated at the district, province and finally country level by the

210 corresponding statistics offices. For obvious practical reasons, most of the agricultural statistics

211 are based on sampling at the district level, rather than on an exhaustive census. For the specific

212 case of rice planted areas, a three-stage sampling is applied in each district, at the commune,

213 village, and farming household levels. For the retained communes, enumerators report to the

214 District Statistics Offices the rice planted areas in the fields owned by the selected farming 
215 households in the selected villages. The collected data are then forwarded to the Province

216 Statistics Offices, and finally the General Statistics Office (GSO) (Food and Agriculture

217 Organization of the United Nations 2002). Around 100000 farming households in the whole

218 country are involved in the rice area sampling, out of a total of more than 9 million households

219 that grow paddy (Food and Agriculture Organization of the United Nations 2002). This

220 hierarchical acquisition scheme is very time- and resource-consuming. Moreover, its accuracy is

221 intrinsically limited by the errors consecutive to the sampling.

222

223 The General Statistics Office publishes annual agricultural statistics for each of the 58 provinces

224 and 5 centrally-controlled municipalities in Vietnam. For paddy rice agriculture, these statistics

225 comprise planted area, production and yield. The different crops of rice are gathered into three

226 categories: Spring (labelled as "Đông Xuân" in the Vietnamese database), Autumn ("Hè Thu")

227 and Winter ("Mùa") seasons. The figures for each of these three seasons in 2007 for every

228 province of the Mekong River Delta are presented in Table 2.

229

230 Table 2. Planted area of rice by province for the three rice seasons in 2007 from national 231 statistics

\begin{tabular}{|l|r|r|r|}
\cline { 2 - 4 } \multicolumn{1}{c|}{} & \multicolumn{3}{c|}{ Planted area in 2007 (ha) } \\
\cline { 2 - 4 } \multicolumn{1}{c|}{} & Spring & \multicolumn{1}{c|}{ Autumn } & \multicolumn{1}{c|}{ Winter } \\
\hline Long An & 234300 & 178800 & 15400 \\
\hline Tiền Giang & 83400 & 163400 & 0 \\
\hline Bến Tre & 20700 & 24200 & 34800 \\
\hline Trà Vinh & 49700 & 81100 & 93200 \\
\hline Vĩnh Long & 68500 & 89800 & 0 \\
\hline
\end{tabular}




\begin{tabular}{|l|r|r|r|}
\hline Đồng Tháp & 208400 & 238700 & 0 \\
\hline An Giang & 230600 & 282700 & 7300 \\
\hline Kiên Giang & 265300 & 266500 & 51200 \\
\hline Cần Thơ & 92100 & 115800 & 0 \\
\hline Hậu Giang & 79000 & 110300 & 0 \\
\hline Sóc Trăng & 140700 & 158900 & 25900 \\
\hline Bạc Liêu & 33900 & 53300 & 62600 \\
\hline Cà Mau & 0 & 36000 & 87100 \\
\hline Total & 1506600 & 1799500 & 377500 \\
\hline
\end{tabular}

234 The correspondence between these three categories (Spring, Autumn, and Winter) and the 235 agricultural seasons presented in the previous sub-section (Winter-Spring, Summer-Autumn, 236 Autumn-Winter, and Main wet season) is not straightforward, and has to be discussed. The

237 diversity of harvesting time and the differences in rice cropping patterns from the North to the 238 South of Vietnam tend to make such a countrywide categorization irrelevant.

240 Figure 2 shows the proportion of each of the Spring, Autumn and Winter crops that are planted

241 in each province in 2007 according to the statistics. The inland provinces grow mostly Spring 242 and Autumn crops, with no or very few Winter crop, which seems paradoxical at first sight as 243 triple-cropping is practised in these regions. The planted area for Autumn rice is higher than for 244 Spring rice in the statistics, while in reality, the Winter-Spring and Summer-Autumn planted 245 areas are similar, with the Autumn-Winter coming as an optional third crop in a small number of 246 fields. Therefore, it can be assumed that in the inland provinces, the Spring statistical category 247 accounts for the Winter-Spring crop, and the Autumn category for the sum of the Summer- 
248 Autumn and Autumn-Winter crops. Reversely, the coastal provinces grow the three kinds of rice

249 (except Cà Mau with no Spring rice), while the dominant patterns are single and double-

250 cropping, with marginal areas growing irrigated triple-rice, especially in Soc Trang. It can then

251 be inferred that, in the coastal provinces, the Spring category represents the Winter-Spring rice,

252 the Autumn category corresponds to the Summer-Autumn rice and the Winter category gathers

253 the main wet season (Mua) from the double-rice pattern and the Autumn-Winter season from the

254 triple-rice pattern. Therefore, it seems that the three rice seasons described in the statistics do not

255 cover the same categories in the coastal provinces and in the inland provinces. Table 3 gives a

256 synthetic view of the supposed correspondence between these seasons from the statistical

257 database and the agricultural seasons from Table 1.

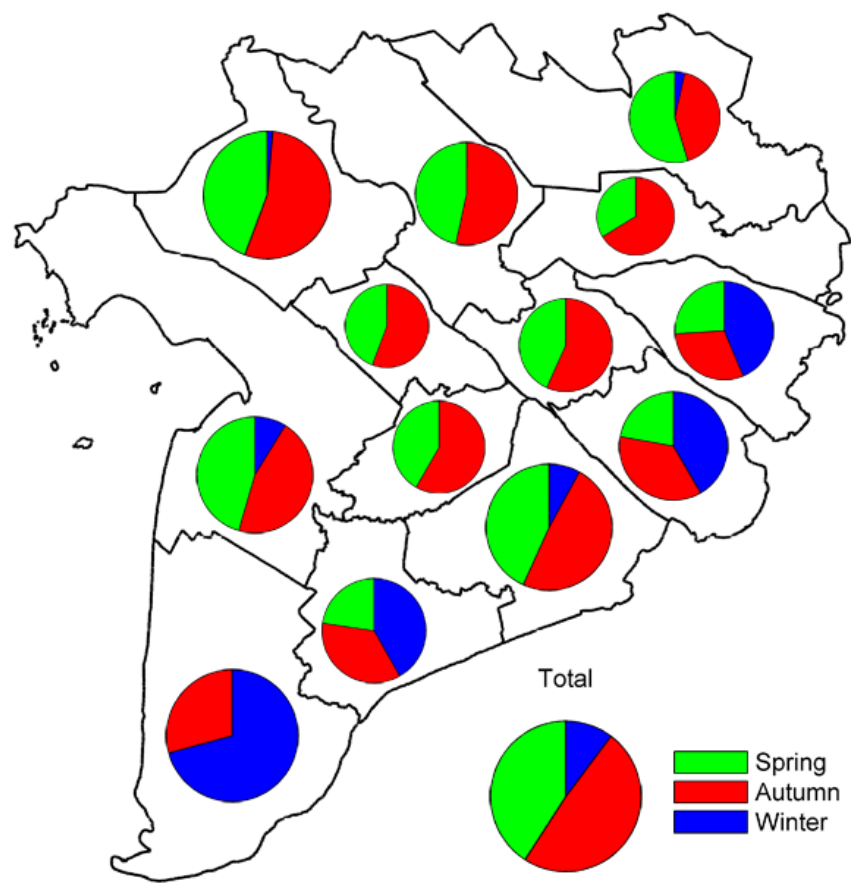

259 Figure 2. Proportion of Spring, Autumn and Winter rice planted in each province in 2007. 
Table 3. Correspondence between seasons from the statistical database and agricultural

262 seasons.

\begin{tabular}{|c|c|c|c|}
\hline \multirow{2}{*}{ English } & \multirow{2}{*}{ Vietnamese } & \multicolumn{2}{|c|}{ Correspondence with agricultural seasons } \\
\cline { 3 - 4 } & \multirow{2}{*}{ name } & Inland provinces & Coastal provinces \\
\hline Spring & Đông Xuân & 1 & $(1)$ \\
\hline Autumn & Hè Thu & $2+3 \mathrm{a}$ & 2 \\
\hline Winter & Mùa & $(3 \mathrm{~b})$ & $(3 \mathrm{a})+3 \mathrm{~b}$ \\
\hline
\end{tabular}

264

\section{ASAR APP rice seasons map for An Giang province data}

266 In a previous work (Bouvet et al. 2009), maps of the rice planted areas have been produced at a 267 spatial resolution of $30 \mathrm{~m}$ for the three rice seasons in 2007 in the province of An Giang. These

268 maps have been obtained by applying a $3 \mathrm{~dB}$ threshold on the polarization ratio $\mathrm{HH} / \mathrm{VV}$ on a 269 time-series of ASAR Alternating Polarization Precision image (APP) data at incidence IS2 $270\left(19.2^{\circ}-26.7^{\circ}\right)$. The results have been validated using a land-use Geographic Information System 271 (GIS) database covering one district, leading to a pixel-based accuracy of 89.9\%. Moreover the 272 estimated rice area in the Winter-Spring season for the whole province (229694 ha) has been 273 compared to the preliminary statistics from the GSO (224273 ha), with a $2.4 \%$ difference 274 between the two figures.

275 These maps will be used complementarily to the statistical data for further validation of the new 276 methods presented in this paper. 


\section{ASAR WSM data}

280 The ASAR instrument is a C-band SAR instrument (5.6cm wavelength) onboard the European 281 satellite ENVISAT, which was launched in 2002, with multiple resolution, incidence, and 282 polarization ability. Among the five operating modes of ASAR (Image Mode, Alternating 283 Polarization, Wide Swath Mode, Wave Mode and Global Monitoring), only the Wide Swath

284 Mode, using the ScanSAR technique, offers a wide enough swath (around 400km) with a spatial 285 resolution adapted to accurate regional monitoring (around 150m, with a pixel spacing of $75 \mathrm{~m}$ ).

286 The incidence angle in each image ranges from $17^{\circ}$ to $42^{\circ}$.

287 Extensive time-series of Wide Swath mode Medium resolution (WSM) data have been acquired 288 during the year 2007 over the Mekong Delta, with polarization HH, in order to monitor rice 289 agriculture by means of methods based on the backscatter temporal change.

290 Studies on the assessment of classification methods based on temporal change (Bouvet et al. 291 2010) and previous studies using RADARSAT (Ribbes and Le Toan 1999) have emphasized the 292 necessity of a high temporal observation frequency (e.g. around every ten days) to achieve 293 acceptable classification accuracy. The time lapse between repeat-pass orbits of ENVISAT is 35 294 days. In order to increase the observation frequency, data from three different satellite tracks 295 have been ordered: tracks 32 and 304 in descending pass and track 412 in ascending pass. Each 296 of the three tracks covers the delta entirely, as can be seen in Fig. 3. The other tracks that would 297 have covered the whole area have been left for the acquisition of Alternating Polarization data. 


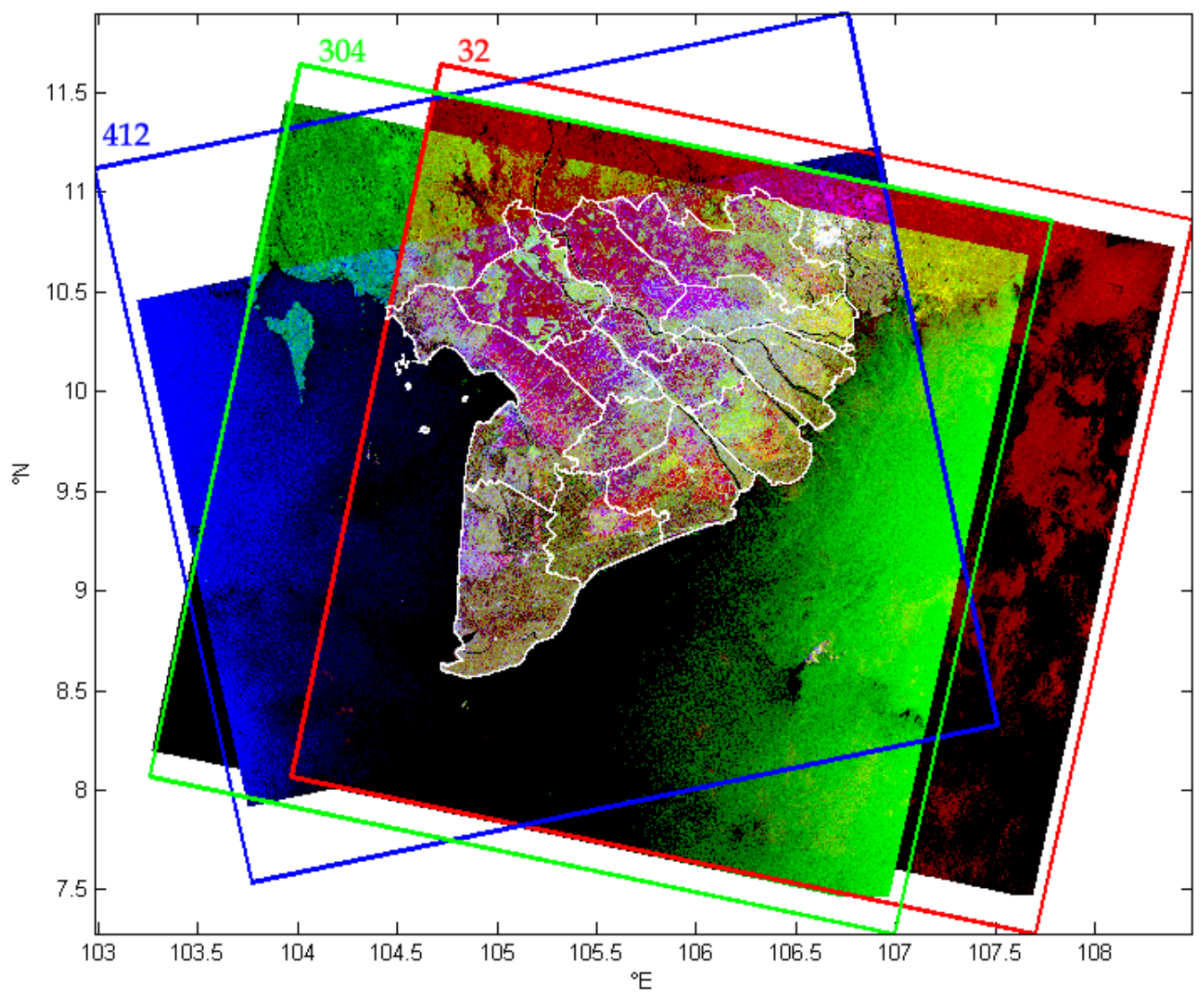

300 Figure 3. Colour-composite image of three WSM data from the three acquired tracks, with 301 ascending tracks 32 and 304 in red and green respectively, and descending track 412 in blue. The frames of the three tracks are presented in the corresponding colours.

304 The data acquisition sequence is the following: track 304, track 412, track 32 in intervals of 305 respectively 7 and 9 days, followed by the next sequence 19 days later. Therefore, in this three306 track configuration, the biggest time-lapse between two consecutive observations is 19 days, 307 with a mean acquisition interval of 11.7 days. The improvement is thus significant compared to 308 the single track acquisition frequency of one image every 35 days. 
309 Table 4 lists the available dates for the three tracks. Track 412 is the most complete, with all the

3102007 satellite passes successfully acquired. The last acquisition for track 304 is missing, and the

311 dataset for track 32 is incomplete, with only 6 acquisitions.

312

313 Table 4. List of available dates in each track. Hyphens (-) indicate missing acquisitions.

\begin{tabular}{|c|c|c|}
\hline $\mathbf{3 0 4}$ & $\mathbf{4 1 2}$ & $\mathbf{3 2}$ \\
\hline 9 January & 16 January & - \\
\hline 13 February & 20 February & 1 March \\
\hline 20 March & 27 March & 5 April \\
\hline 24 April & 1 May & 10 May \\
\hline 29 May & 5 June & 14 June \\
\hline 3 July & 10 July & 19 July \\
\hline 7 August & 14 August & - \\
\hline 11 September & 18 September & - \\
\hline 16 October & 23 October & 1 November \\
\hline - & 27 November & - \\
\hline
\end{tabular}

314

315 The acquisition dates of the three tracks are plotted in Fig. 4 together with the agricultural

316 seasons of the rice calendar described in II.A 


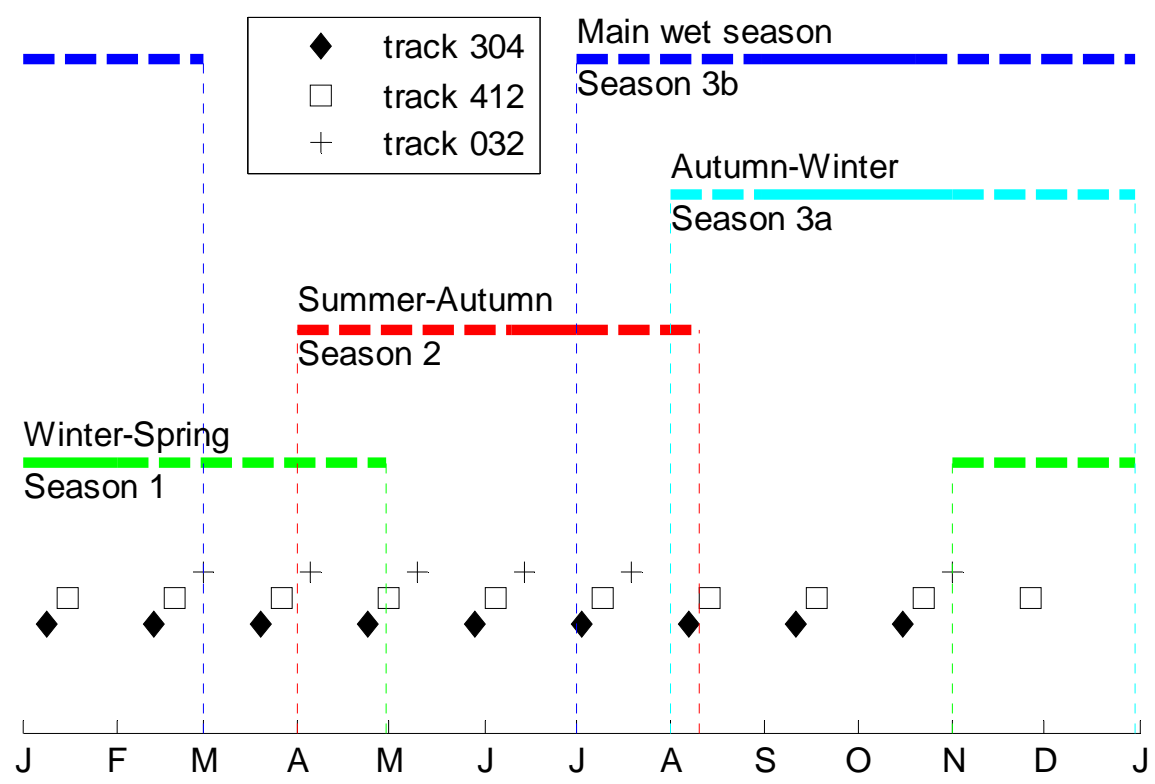

319 Figure 4. Rice calendar in the Mekong delta and dates of the available ASAR WSM data. For

320 each rice crop, dashed lines represent the periods during which the beginning and the end of the crop can take place (spatial and interannual variability).

323 The conditions under which observations from different looking angles can be used together are

324 discussed in the next section.

325 The pre-processing of the WSM data is done with the Gamma GEO software (Gamma Remote 326 Sensing, Switzerland) and consists in the calibration of the SAR data and its geocoding with the 327 elevation data from the DEM of SRTM at 3 arcseconds, and projected to lat/lon coordinates at 328 the resolution of SRTM, corresponding to around 92m per pixel in latitude and longitude. 


\section{III. MAPPING METHOD}

\section{A. Rationale}

337 The principle of this rice mapping method is to detect rice areas through the increase of their co-

338 polarized backscatter intensity between two repeat-pass acquisitions when the first acquisition

339 occurs at the flooding stage, i.e. when the backscatter is low because of the specular reflection

340 over water, and the second acquisition occurs when the rice plants have started to grow, i.e.

341 when the double-bounce provides high backscatter. Other classes are expected to remain

342 relatively stable in comparison. The method has already proven effective at $23^{\circ}$ incidence and

$343 \mathrm{HH}$ or VV polarizations in past studies. The innovative aspect relies here in the use of multi-

344 track acquisitions to increase the observation frequency and in the use of wide-swath data to

345 ensure a regional coverage. For each pixel, the local incidence angle is different for the three

346 tracks, and within one image, the incidence angles varies from $17^{\circ}$ in the near range to $42^{\circ}$ in the

347 far range. The conditions under which such heterogeneous data can be used together have to be

348 examined so as to develop a classification method that is invariant to the temporal and spatial

349 variation in the incidence angle. The scatterometer measurements presented in (Inoue et al.

3502002 ) and already mentioned in the introduction have been conducted at $25^{\circ}, 35^{\circ}, 45^{\circ}$ and $55^{\circ}$

351 incidence. This study has shown that the value of $\mathrm{C}$-band $\mathrm{HH}$ backscatter changes with the

352 incidence for a given phenological stage. A classification feature based on the value of the

353 backscattering intensity is thus unsuitable for the case of wide-swath data from different tracks.

354 For example, the detection of flooded fields by applying a threshold on the $\mathrm{HH}$ images to

355 identify the low backscatter areas would not be relevant because the threshold would have to

356 change with the local incidence angle within an image and between tracks. However, the 
357 backscatter increase from flooding and transplanting to heading exceeds $9 \mathrm{~dB}$ under any

358 incidence angle. A classification feature based on a measurement of the temporal increase of

359 backscatter between two consecutive acquisitions within a single track would therefore be

360 efficient to map rice regardless of the track and regardless of the location of the pixel in the

361 image. The temporal change is preferably measured by the ratio of intensities between two dates

362 (i.e. the difference in $\mathrm{dB}$ ) rather than by the difference of intensities, the latter producing larger

363 classification errors in regions with a high backscatter than in regions with a low backscatter,

364 contrarily to the former for which the classification error is independent on the backscatter

365 intensity (Rignot and van Zyl 1993). Multi-track and multi-temporal classification features based

366 on the combination of temporal intensity ratios will therefore be developed in this paper for the

367 detection of rice fields.

\section{B. Algorithm description}

370 Computing the ratio of two SAR intensity images enhances the incertitude due to speckle. It is

371 therefore necessary to reduce the speckle noise before producing ratio images. In this study, the

372 backscatter images have been spatially filtered using an enhanced Lee filter (Lopes et al. 1990)

373 implemented in the ENVI software (ITT Visual Information Solutions), with a $5 \times 5$ window size.

374 The initial number of looks of the data is 3 in azimuth and 7 in range. The equivalent number of 375 looks, defined as mean ${ }^{2} /$ variance, is calculated to be around 12 in the geocoded WSM images, 376 and around 150 in the filtered images.

377 Figure 5 is a synoptic view of the different steps involved in the mapping algorithm, which will 378 be described in the following sub-sections. 


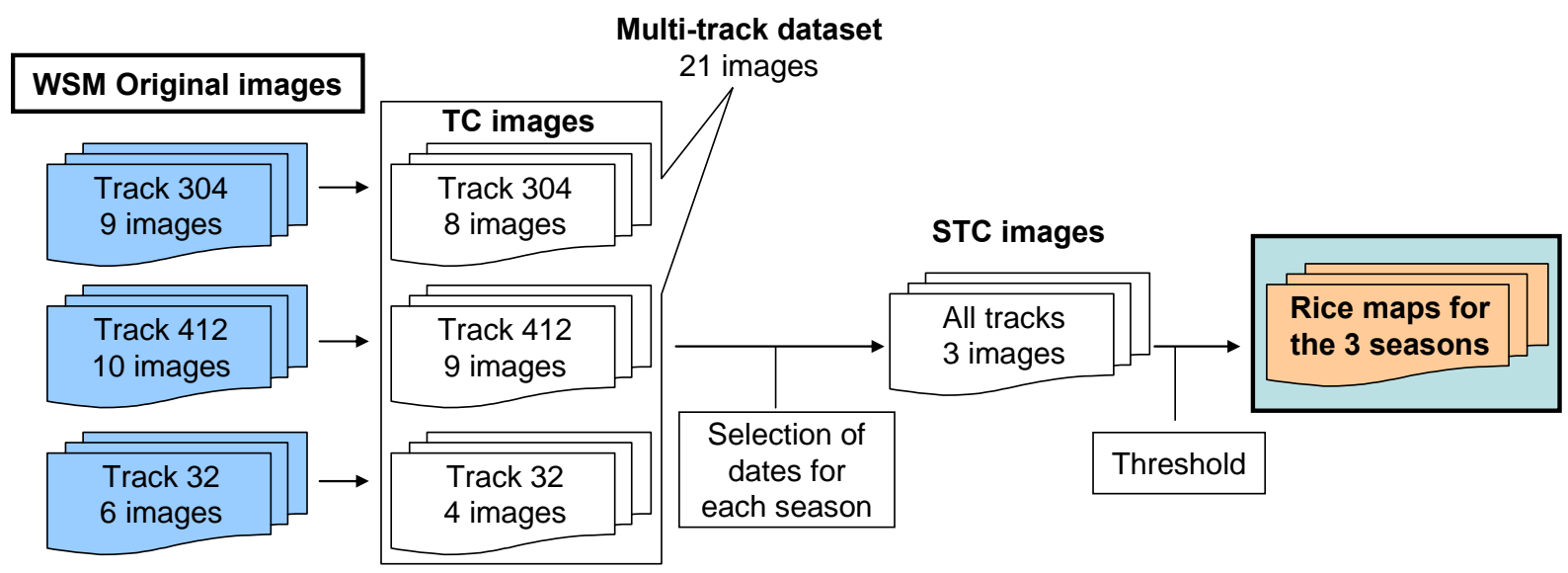

Figure 5. Synoptic view of the mapping algorithm.

382 Out of the twenty-five WSM images available in 2007, temporal change (TC) images are created

383 by computing the ratio between two spatially filtered backscatter intensity images acquired

384 within a track and separated by one satellite repeat pass (35 days): $\mathrm{TC}=\mathrm{HH}_{\mathrm{d}+35} / \mathrm{HH}_{\mathrm{d}}$. These TC

385 images compose a multi-track dataset of twenty-one images: eight from track 304, nine from

386 track 412, and four from track 32.

387 The mapping algorithm consists in applying a threshold on these TC images in order to detect

388 the rice fields that are flooded at the corresponding dates, characterized by their post-flooding

389 backscatter increase. To detect all the rice areas planted during one season, one single TC image

390 may however not be enough, because of shifts in the planting calendar, even within a province.

391 The rice maps retrieved from the TC images must therefore be aggregated to produce seasonal

392 maps. This is equivalent to applying the threshold directly on a seasonal temporal change (STC)

393 classification feature, made up by taking the maximum value of the TC images among the dates

394 corresponding to each season. The next sub-sections discuss how the threshold should be

395 chosen, and how the dates corresponding to each season and each province can be selected. The 
396 study will be conducted for Season 2 and Season 3 only, as the complete mapping of Season 1

397 (Winter-Spring) would require data from the end of 2006.

\section{Defining the value of the classification threshold}

400 Under the assumption of gamma distributed SAR intensities and uncorrelated images, a 401 theoretical expression of the optimal classification threshold $t_{\text {opt }}$ can be found for the two-class 402 problem - a rice class and a non-rice class - when the classification feature is a single TC image 403 (Bouvet et al. 2010):

$$
t_{\text {opt }}=\sqrt{T C_{n r} T C_{r}} \cdot \frac{\sqrt{\frac{T C_{r}}{T C_{n r}}}\left(\frac{p(n r)}{p(r)}\right)^{\frac{1}{2 L}}-1}{\sqrt{\frac{T C_{r}}{T C_{n r}}}-\left(\frac{p(n r)}{p(r)}\right)^{\frac{1}{2 L}}}
$$

405 where $\mathrm{nr}$ and $\mathrm{r}$ denote respectively the non-rice and the rice classes, and $\mathrm{p}(\mathrm{nr})$ and $\mathrm{p}(\mathrm{r})$ denote the a priori probabilities of the non-rice class and of the rice class, i.e. the percentage cover of non407 rice and rice in the landscape. $\mathrm{TC}_{\mathrm{nr}}$ and $\mathrm{TC}_{\mathrm{r}}$ represent the mean temporal change $408<<\mathrm{HH}_{\mathrm{d}+35}>/<\mathrm{HH}_{\mathrm{d}}>$ of the non-rice and the rice classes $\left(\mathrm{TC}_{\mathrm{r}}>\mathrm{TC}_{\mathrm{nr}}\right.$ ), and $\mathrm{L}$ is the number of looks 409 of the images (or the equivalent number of looks in case of filtered images). Ground-truth 410 information is required to assess the values of $\mathrm{p}(\mathrm{nr}), \mathrm{p}(\mathrm{r}), \mathrm{TC}_{\mathrm{nr}}$ and $\mathrm{TC}_{\mathrm{r}}$, and consequently the 411 threshold $t_{\text {opt }}$ to use in the classification. It is shown that the class parameters $\mathrm{TC}_{\mathrm{nr}}$ or $\mathrm{TC}_{\mathrm{r}}$ are 412 linked by a simple relationship to $\mathrm{TC}_{\max , n r}$ and $\mathrm{TC}_{\max , \mathrm{r}}$, which are the values where the 413 probability density functions (pdf) of TC for the corresponding class is the highest, e.g. for the 414 non-rice class:

$$
T C_{n r}=\frac{L+1}{L-1} T C_{\max , n r}
$$


416 and likewise for the rice class.

417 For the case of STC images, equations (1) and (2) do not apply strictly because the pdf of STC is 418 different from the pdf of TC. However, as the pdf of STC cannot be expressed theoretically and 419 is not expected to differ much from that of TC, equations (1) and (2) will be used on the STC.

420 In the present study, the rice maps retrieved in (Bouvet et al. 2009) from the APP dataset can be 421 used as ground truth over the An Giang province to calculate $\mathrm{p}(\mathrm{nr})$, $\mathrm{p}(\mathrm{r})$, and to plot the 422 histograms of STC for the rice and the non-rice classes, for Season 2 (Summer-Autumn) and 423 Season 3 (Autumn-Winter), in order to estimate $\mathrm{STC}_{\max , \mathrm{nr}}$ and $\mathrm{STC}_{\mathrm{max}, \mathrm{r} \text {. }}$ The proportion of rice $424 \mathrm{p}(\mathrm{r})$ calculated in the APP maps is $62.7 \%$ for Season 2 and $20.6 \%$ for Season 3 . The normalized 425 histograms of these seasonal classification features are plotted in Fig. 6 for the two considered 426 classes, based on the pixels identified as rice or non-rice in the maps derived from APP, which 427 have been spatially degraded and projected to the geocoded WSM data. These normalized 428 histograms estimate the pdf of STC for the two classes. The $\mathrm{STC}_{\text {max }}$ parameters are assessed for 429 each class by identifying the $\mathrm{STC}$ value where the histogram is maximal, and the $\mathrm{STC}_{\mathrm{r}}$ and $430 \mathrm{STC}_{\mathrm{nr}}$ class parameters are retrieved using equation (2). The values corresponding to the optimal 431 classification threshold $\mathrm{t}_{\mathrm{opt}}$ for Summer-Autumn and Autumn-Winter are then found from (1) to 432 be respectively $4.49 \mathrm{~dB}$ and $4.53 \mathrm{~dB}$. 

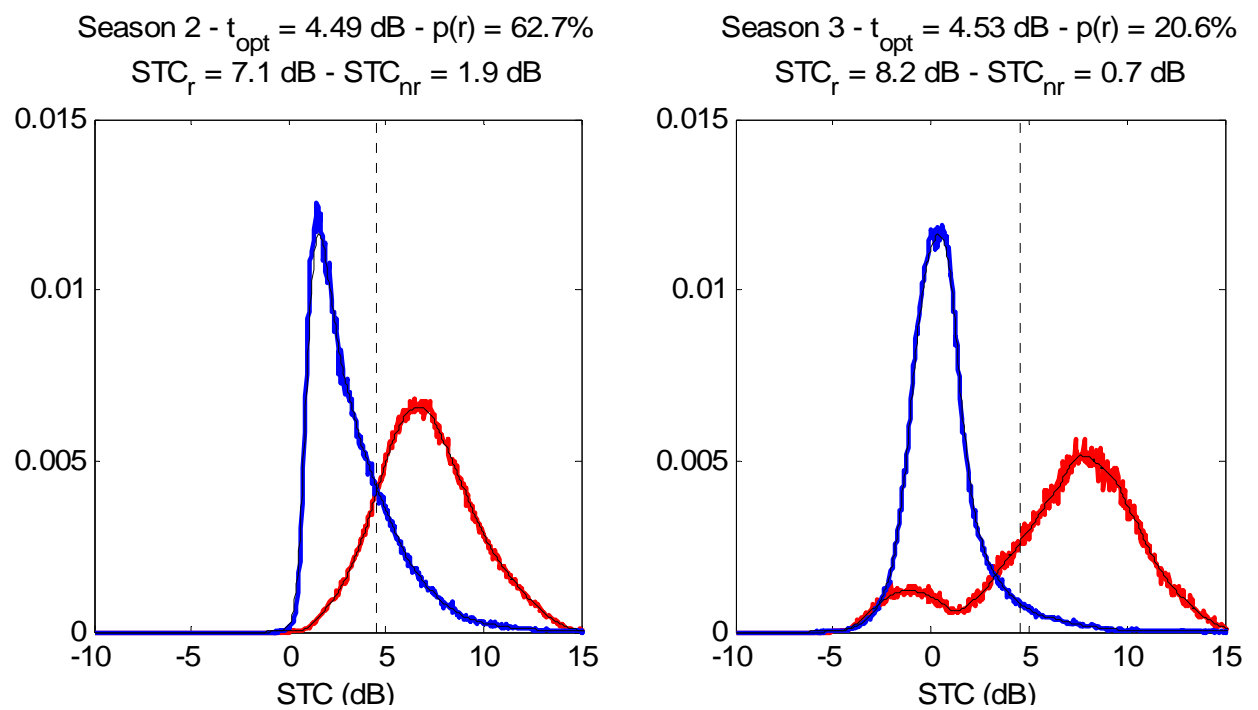

435 Figure 6. Histograms of the STC classification features for Season 2 (left) and Season 3 (right), 436 for the rice class (red) and the non-rice class (blue). Vertical dashed black lines represent the theoretical optimal classification threshold $\mathrm{t}_{\mathrm{opt}}$ retrieved from the histograms.

439 In most applications, no such extensive ground truth data is available. Quite commonly, the 440 location of a few sample areas of rice and non-rice are known and allow an approximate 441 estimation of $\mathrm{STC}_{\mathrm{nr}}$ and $\mathrm{STC}_{\mathrm{r}}$. The class proportions, $\mathrm{p}(\mathrm{nr})$ and $\mathrm{p}(\mathrm{r})$, remain however generally 442 unknown and have to be assumed to be equal to 0.5 , which leads to a simplified expression of 443 the optimal threshold: $t_{o p t}=\sqrt{S T C_{n r} S T C_{r}}$. In less favourable cases when no ground 444 information is available at all, like here in the other provinces of the Mekong delta, the 445 theoretical value of the optimal classification threshold cannot be retrieved. In that case, the only 446 option is to use values from literature. Previous studies have suggested a threshold of $3 \mathrm{~dB}$ (Le 447 Toan et al. 1997; Liew et al. 1998; Ribbes and Le Toan 1999), which can be used as a baseline 448 algorithm. This value is significantly lower than the values around $4.5 \mathrm{~dB}$ found for An Giang. 449 Figure 7 presents the pixel-based classification accuracy for the An Giang province, calculated 
450 from the APP-derived maps, as a function of the retained classification threshold, with a 451 particular focus on the true optimal threshold, leading to the maximal accuracy, and on the $3 \mathrm{~dB}$ 452 threshold. The figure indicates that, for this dataset, a relatively wide range of threshold values 453 roughly between $3 \mathrm{~dB}$ and $5 \mathrm{~dB}$ in Summer-Autumn, and between $3 \mathrm{~dB}$ and $7 \mathrm{~dB}$ in Autumn454 Winter - lead to similarly high pixel-based accuracies. In particular, the use of the baseline 455 algorithm (3dB threshold) leads to only slightly suboptimal results, with an additional error of 456 about $2 \%$ compared to the optimal accuracy. It was therefore chosen to use the $3 \mathrm{~dB}$ threshold for 457 the mapping of rice areas over the whole Mekong delta.

458

$$
\text { Season } 2-\mathrm{t}_{\mathrm{opt}}=4.00 \mathrm{~dB}
$$



Season $3-\mathrm{t}_{\text {opt }}=4.80 \mathrm{~dB}$

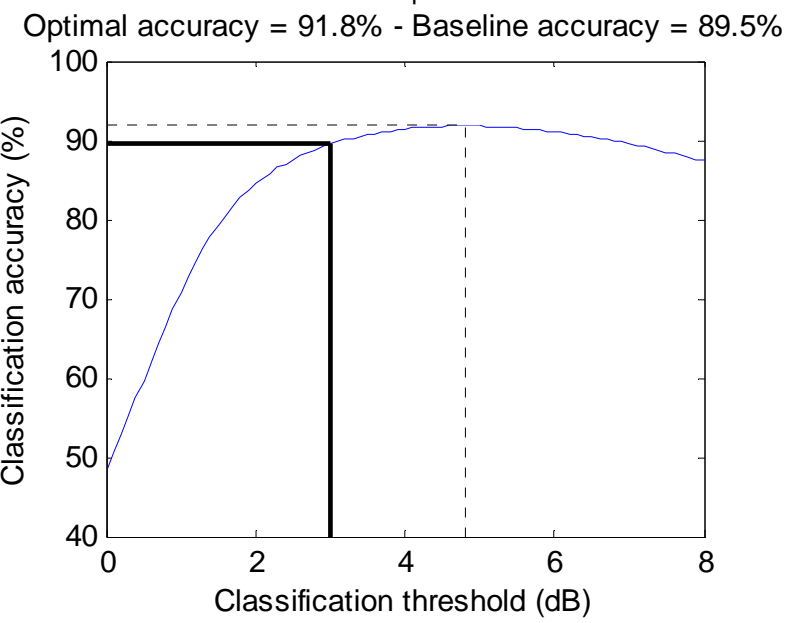

460 Figure 7. Classification accuracy as a function of the retained classification threshold for season

4612 (left) and season 3 (right) in An Giang province. The true optimal threshold $t_{\text {opt, }}$ leading to the 462 maximal accuracy, is calculated and plotted in dashed line, and the baseline $3 \mathrm{~dB}$ threshold and 463 corresponding accuracy are plotted in full bold line. 


\section{Creating STC images}

468 Because of the lack of WSM images in the end of 2006, the first crop in 2007 - the Winter-

469 Spring crop - cannot be mapped exhaustively. The study therefore focuses on the other rice

470 seasons. One STC image is created for Season 2 (the Summer-Autumn crop) and another one for

471 Season 3 (i.e. both the main wet season and the Autumn-Winter season because of their 472 simultaneity).

473 In some areas with homogeneous cropping patterns, the simple knowledge of agricultural

474 calendars should be sufficient to select the TC images to be used for the production of the STC

475 images. For the case of the Mekong River Delta however, the variety of cropping patterns and 476 calendars between provinces has to be accounted for. Figure 8 shows intermediate rice maps 477 obtained by considering groups of up to three TC images acquired during a short period of time 478 and belonging to different tracks. The groups are composed of one TC image from track 412 479 together with the preceding TC image from track 304 (seven days before) and the following TC 480 image from track 32 (nine days later) when available, which corresponds to the lines in Table 4. 481 Pixels in white (values above the $3 \mathrm{~dB}$ threshold for at least one of the TC images in the group) 482 therefore represent the paddy fields that are at the flooding stage around the indicated date. This 483 reflects well the complexity of the cropping patterns in the region, as at each date, flooded fields 484 are present somewhere in the delta. This enhances the need of a precise selection of the TC 485 images at the province level for the production of STC images. 

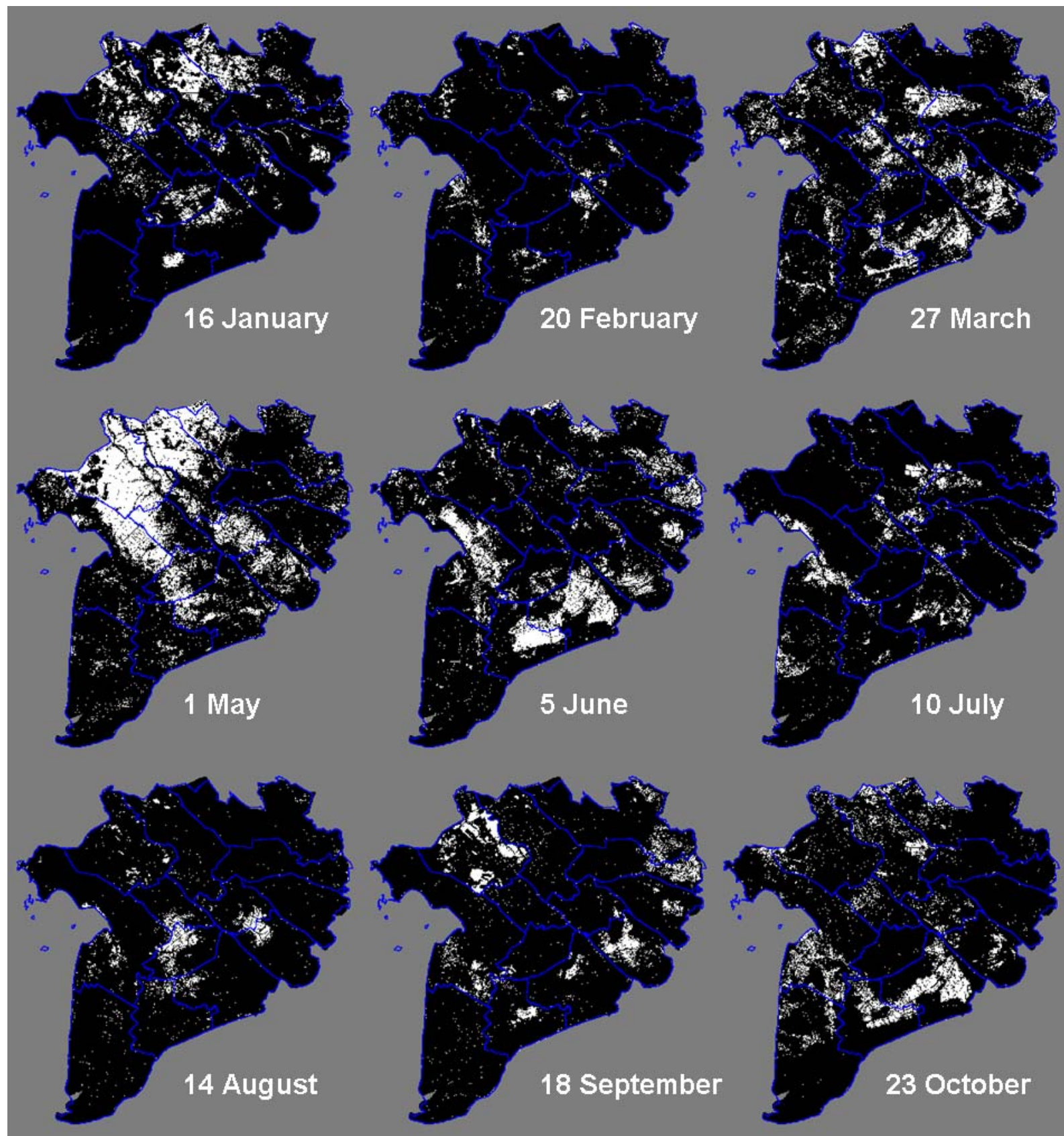

Figure 8. Rice maps derived from nine groups of up to three TC images. Pixels in white

490 group, and pixels in black with a TC value below the threshold for all the images in the group. 
492 In this study, we chose to use time-series of NDVI as ancillary data to select the TC images. The 493 VGT-S10 products of the VEGETATION-2 instrument on-board SPOT-5 have been used. They 494 consist in 10-day syntheses of the four spectral bands of the instrument at a spatial resolution of $4951 \mathrm{~km}$. The NDVI, which is the normalized difference of the near infrared and red reflectances, is 496 a proxy for the chlorophyll content within one pixel, and therefore for the live green vegetation.

497 The 36 VGT-S10 products of the year 2007 covering the Mekong Delta were downloaded and 498 processed to produce NDVI time-series. A cloud-removal filter inspired on the Best Index Slope 499 Extraction (BISE) algorithm (Viovy et al. 1992) was applied on the NDVI time-series. The dates 500 of local crop calendars are estimated by a visual interpretation of the vegetation cycles depicted 501 in the NDVI time-series at selected pure pixels among each province. A sufficient number of 502 pixels should be chosen to represent the cropping pattern diversity in each province (i.e. mainly 503 double and triple cropping) and the variety in each cropping pattern (from early to late crops).

\section{RESULTS AND DISCUSSION}

\section{A. Mapping results}

509 A $3 \mathrm{~dB}$ threshold is applied on the two STC images that have been created by keeping the 510 maximum value of the TC images selected within each province for Season 2 and Season 3. The

511 isolated rice pixels or the very small patches detected as rice (less than 40 pixels) are removed 512 from the rice class because they are likely to be errors due to remaining speckle.

513 Figure 9 shows the rice maps obtained in the whole Mekong delta. The map depicts the areas 514 where rice is grown in Season 2 only in green, in Season 3 only in red, in both seasons in 
515 yellow, and the areas where no rice is detected in black. As Season 1 is missing, it is reasonable 516 to assume that in inland provinces, the green areas actually correspond to double-rice patterns 517 and the yellow areas to triple-rice patterns. This map exhibits cropping patterns that are very 518 similar to those presented by (Sakamoto et al. 2006), which include coarser resolution rice maps 519 of 2002 and 2003 derived from MODIS and a land-use map of 2002 provided by the Sub520 National Institute for Agricultural Planning and Projection of Vietnam. In particular, in An 521 Giang province, the WSM map illustrates the well-known expansion of triple-rice (labeled as 522 "both seasons" in this case) between 2002-2003 and 2007.

523 Table 5 lists the rice areas for both seasons calculated from these rice maps. 524 




Figure 9. Rice map derived from the STC images for Season 2 and Season 3. 


\begin{tabular}{|c|c|c|}
\cline { 2 - 3 } \multicolumn{1}{|c|}{} & Season 2 & Season 3 \\
\hline Long An & 123461 & 23817 \\
\hline Tiền Giang & 64666 & 39444 \\
\hline Bến Tre & 24531 & 8981 \\
\hline Trà Vinh & 81179 & 54896 \\
\hline Vĩnh Long & 66903 & 25465 \\
\hline Đồng Tháp & 203720 & 32927 \\
\hline An Giang & 263321 & 78725 \\
\hline Kiên Giang & 257890 & 20120 \\
\hline Cần Thơ & 73293 & 21586 \\
\hline Hậu Giang & 56078 & 36819 \\
\hline Sóc Trăng & 155938 & 28954 \\
\hline Bạc Liêu & 67470 & 26635 \\
\hline Cà Mau & 40155 & 795 \\
\hline
\end{tabular}

\section{B. Validation}

534 A visual comparison of the rice maps in An Giang is presented in Figure 10 between the new

535 rice maps derived from WSM and the rice maps derived from APP data in a previous study.

536 Although the classification features in the two SAR methods are based on different physical

537 mechanisms, the results compare very well to each other, which demonstrates the robustness of

538 both methods for the identification of rice fields. The pixel-based accuracy, which corresponds

539 to the percentage of pixels that are classified in the same category (rice or non-rice) by the two

540 methods, is equal to $81.3 \%$ and $89.5 \%$ for Season 2 and Season 3 respectively. When 541 considering the joint mapping results at the two seasons, four classes are distinguished: no rice, 
542 rice in Season 2 only, rice in Season 3 only, and rice in both seasons, similarly to the larger map

543 in Fig. 9. The normalized confusion matrix for the four classes, with the APP map considered as

544 reference data and the WSM map as classification data, is given in Table 6. Each cell in the table

545 contains the percentage of pixels in the scene that are classified in the class defined by its

546 column and by its line in the APP and WSM maps respectively. The overall classification

547 accuracy is therefore equal to the sum of the figures in the diagonal: $75.8 \%$. Most of the

548 classification error is commission error, i.e. pixels classified as non-rice in the APP map are

549 classified as rice in the WSM map (mostly Season 2 and both seasons). Two sources of

550 commission are identified from Fig.10: a) a small part of the rivers are detected as rice by the

551 method based on WSM because the backscattering of water can change with wind conditions,

552 and b) with its coarser spatial resolution, the WSM map is not able to discriminate fine features

553 such as roads and channels between fields. As rivers, roads and channels do not change from

554 year to year, both causes of commission error can be tackled by masking these areas through the

555 use of a GIS land cover database for example.

556

557 

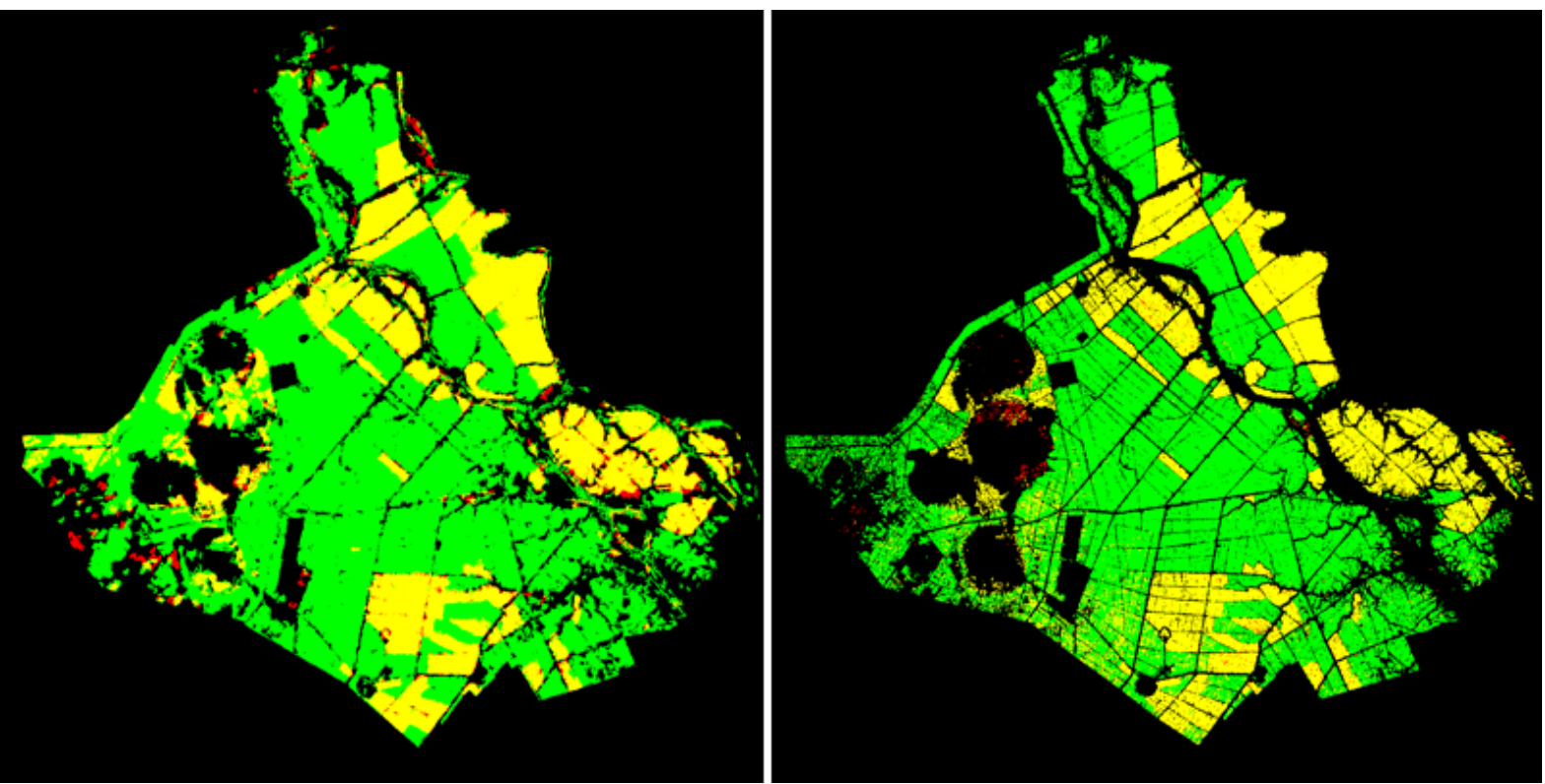

Figure 10. Rice maps derived from the WSM dataset (left) and APP dataset (right) in An Giang for Season 2 and Season 3 in 2007 (same legend as Figure 9).

Table 6. Confusion matrix between classes derived from APP and WSM.

\begin{tabular}{|c|c|c|c|c|c|c|}
\hline & \multicolumn{4}{|c|}{ WSM } & \\
\hline & & no rice & season 2 & season 3 & both seasons & \\
\hline \multirow{4}{*}{ APP } & no rice & $19,57 \%$ & $11,36 \%$ & $1,51 \%$ & $4,48 \%$ & $36,92 \%$ \\
\hline & season 2 & $1,69 \%$ & $39,45 \%$ & $0,12 \%$ & $1,23 \%$ & $42,49 \%$ \\
\hline & season 3 & $0,09 \%$ & $0,09 \%$ & $0,03 \%$ & $0,32 \%$ & $0,52 \%$ \\
\hline & both seasons & $0,34 \%$ & $2,69 \%$ & $0,33 \%$ & $16,71 \%$ & $20,07 \%$ \\
\hline & & $21,69 \%$ & $53,58 \%$ & $1,98 \%$ & $22,74 \%$ & \\
\hline
\end{tabular}

564 The ability of the new mapping method to retrieve planted areas can be tested against the

565 statistical data given by GSO. As suggested in Table 3, the planted areas given for the Autumn

566 category in the statistics has to be compared to the sum of the planted areas retrieved by WSM

567 for Season 2 and Season 3 in the inland provinces, and to the planted areas retrieved for Season 
5682 in the coastal provinces. The corresponding figures are plotted in Fig. 11. The two datasets 569 show a very good agreement $\left(\mathrm{R}^{2}=0.92\right)$ with a root mean square error of 26000 ha per province.

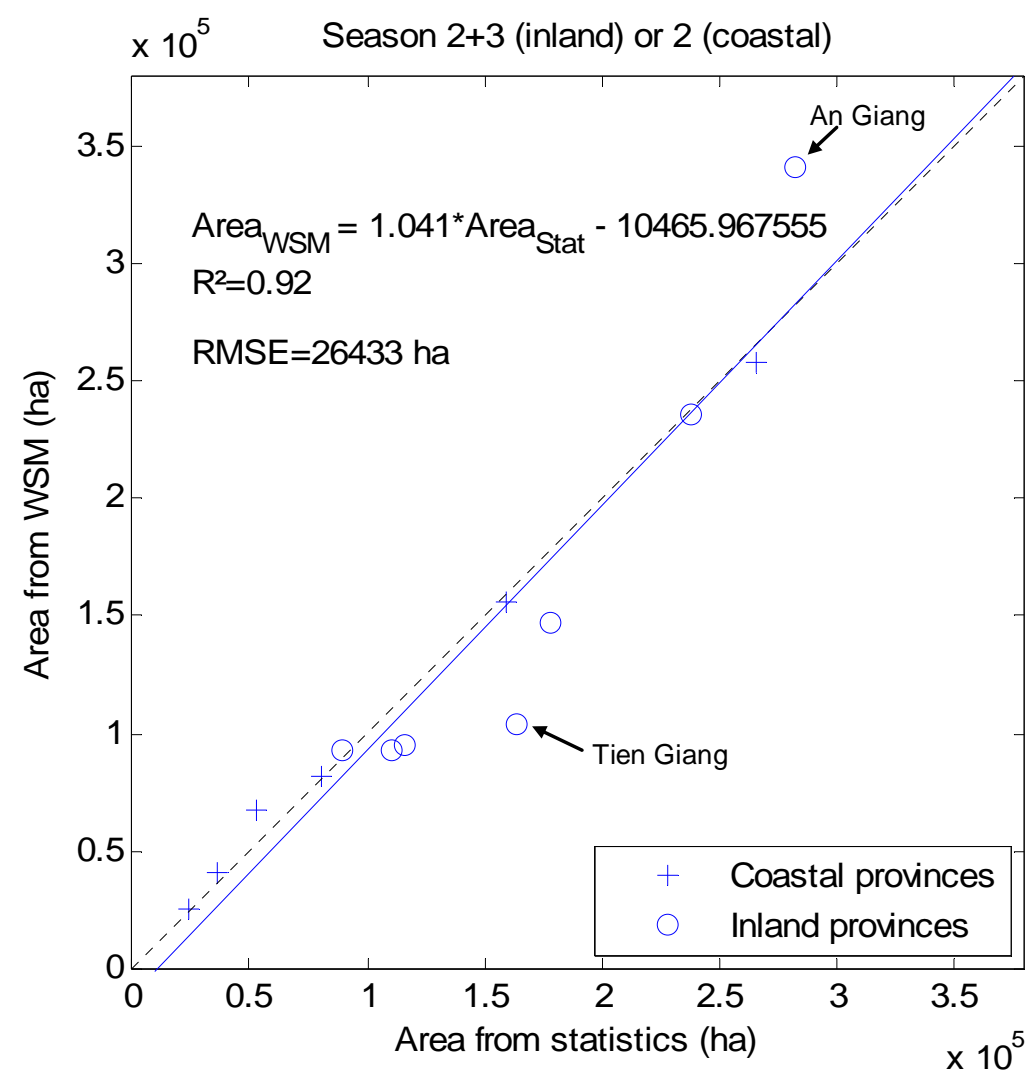

572 Figure 11. Retrieved rice planted areas per province (in ha) for season 2 (coastal provinces) and 573 the sum of Season 2 and Season 3 (inland provinces) vs. statistical rice planted areas in Autumn. The blue line represents the linear regression between the two datasets.

\section{Discussion}

578 As can be seen from Fig. 11, the area estimation is excellent in coastal provinces and a bit less 579 good in inland provinces. One possible reason for this difference could be that the assumption 580 that the Autumn category from the statistical database contains Season 2 and Season 3 in inland 
581 provinces is not totally valid. There might be differences between inland provinces in the 582 definition of seasons by the General Statistics Office. This must not however hide the fact that 583 true sources of error exist. Some sources of error can lead to an overestimation (up to 59000ha in 584 An Giang) or an underestimation (up to 59000ha in Tiền Giang) of the rice planted areas. These 585 sources include the effect of mixed pixels, commission errors (non-rice areas classified as rice) 586 and omission errors (rice areas classified as non-rice).

587 Several types of land use can exhibit a high backscatter increase under certain conditions, thus 588 generating commission errors. These cases can generally be easily discarded by a more detailed 589 analysis of the available SAR time-series. For example, in the Mekong River Delta, a rapid 590 increase in backscatter can happen locally when the seasonal flood recedes, or over permanent 591 water areas (lakes, rivers) because of the wind, resulting in an erroneous detection of rice. The 592 seasonal flood should be relatively easily spotted by detecting low backscatter values during 593 several consecutive repeat-pass acquisitions. Permanent water areas on the other hand can be 594 masked out by applying a threshold on the mean backscatter within a SAR time-series. In the 595 rice growing regions where another major crop is grown (e.g. wheat), confusion could also occur 596 when one image is acquired before harvest and the next one after harvest, which could result in a 597 backscatter increase. But in most cases these crops are not grown simultaneously to rice so the 598 confusion can be avoided by selecting the relevant acquisition dates.

599 The effect of mixed pixels is more important and is directly related to the spatial resolution of 600 the imagery data. In the study area, the agricultural landscape is composed of large surfaces of 601 rice fields separated by smaller non-rice elements such as roads, irrigation channels, dwellings, 602 or vegetable patches, especially in the irrigated areas in the inland provinces. Consequently, 603 many pixels classified as rice actually contain a small proportion of non-rice surface. The 
604 reverse is not true, so mixed pixels globally lead to an overestimation of rice planted areas. This

605 overestimation is more important at coarser resolutions, and has already been illustrated in Fig.

60610 for the An Giang province.

607 The area overestimation due to mixed pixels should also be present in other provinces, but it is 608 not observed in Fig.11. It can be supposed that this overestimation may be at least partially 609 compensated by other error sources that lead to area underestimation, i.e. omission errors. This 610 can happen when SAR data are missing during the few days when the fields are flooded. This is 611 most likely to have happened here for Season 3, when no data could be acquired in track 032.

612 For the extreme case of Tiền Giang, another factor may be involved. The NDVI time-series of 613 three representative selected pixels in the province are plotted in Fig. 12, after smoothing with a 614 central moving average. They all describe a triple-cropping pattern. The green and blue profiles 615 are typical of the well-known Winter-Spring/Summer-Autumn/Autumn-Winter pattern. In the 616 contrary, the red profile differs from this planting scheme, with a peculiar "Spring-Summer" 617 crop (locally named "Xuân Hè") inserted between the Winter-Spring and Summer-Autumn 618 seasons, and no Autumn-Winter crop as the area is reached by the seasonal floods in October619 November. This Winter-Spring/Spring-Summer/Summer-Autumn pattern is reported in (Tanaka 620 1995), only in Tiền Giang province. This minor pattern may be badly detected in the STC 621 images designed for Season 2 and Season 3, and the attribution of each of its three crops to the 622 statistical categories (Spring, Autumn, Winter) is unknown. These two effects combined can 623 explain part of the discrepancies between the WSM and statistical figures in Tiền Giang. 




626 Figure 12. Smoothed NDVI profiles of three pixels representative of the triple-cropping pattern

627 in Tiền Giang province. The dates of the WSM images are represented, as well as the typical crop calendar as in Fig. 4.

\section{CONCLUSION}

632 A novel rice mapping method has been developed, based on former methods using the temporal

633 backscatter change as a classification feature, and adapted to the use of multi-track wide-swath

634 datasets. The effect of the spatial and temporal variation of the incidence angle within the dataset

635 is tackled by using exclusively temporal change images, which are intensity ratio images of two

636 consecutive acquisitions in the same track. This allows increasing significantly the observation

637 frequency and the size of the mapped areas compared to the former methods using single-track 638 narrow-swath datasets. 
639 The study has been conducted in the Mekong River Delta, where rice fields have been mapped

640 over the whole delta for two crops in 2007 (Season 2 and Season 3), using ASAR WSM data.

641 Comparison with a rice map of An Giang province produced with finer-resolution data has

642 shown that the rice detection is very effective with the new methods.

643 Regarding area estimation, an excellent correlation has been obtained when comparing the

644 planted areas retrieved from the rice maps to the planted areas reported in the official statistics.

645 However, this positive result is likely to be due partly to error compensation between

646 overestimation and underestimation sources. As such, the operational use of this method for an

647 accurate area estimation of rice fields should be considered only within an integrated scheme

648 involving other data sources. In well-monitored areas where detailed GIS-based land cover maps

649 are available, which is increasingly common, the method can be applied to the sole pixels known

650 to be agricultural areas in order to reduce commission errors and limit the effect of mixed pixels.

651 In that case, the method can be used as a tool to update this GIS land cover database globally

652 and in near-real time much more effectively than by field investigations. Such operational

653 systems can be based on the data provided by the two existing C-band SARs providing wide-

654 swath data, namely ENVISAT/ASAR and RADARSAT-1 and 2. The limiting factor in this case

655 would be data availability. Given the large choice of operating modes for these sensors,

656 acquisition conflicts between users are very frequent and make it difficult to obtain consistent

657 time-series. For example, in this study, it has been possible to use only three satellite tracks,

658 while under these latitudes, each part of the Earth surface can be observed by 6 tracks in

659 ascending pass and 6 in descending pass, which makes a potential observation interval of about

6603 days. The effective acquisition of this data would require dedicated strategies from the space

661 agencies. In the future, the Sentinel-1 satellite (planned for launch by the European Space 
662 Agency around 2012) should be able to solve this problem, and is therefore a very promising

663 tool for the operational application of the rice mapping method developed in this article.

664 Although tested here only in the Mekong River Delta, the method should be efficient in every

665 rice-growing region, as long as a flooding stage is present. New farming practices have

666 developed in the last years in Vietnam, consisting in direct sowing of germinated seeds on wet

667 soil rather than transplanting of young plants in flooded fields. In that case still, fields are

668 flooded a few days after sowing, so the mapping method is still valid, but as the flooding period

669 is reduced, the need of frequent imagery acquisitions is even harsher.

670 As the method is based on the detection of an event that occurs at the beginning of the rice

671 growing cycle, it is well-suited to the early assessment of cultivated areas. Therefore, if

672 successfully applied on an operational basis, it would be potentially very useful to national

673 statistics officers, decision makers and rice trade professionals.

674

675

676 ACKNOWLEDGEMENT

677 The ENVISAT/ASAR data used in this study were provided by the European Space Agency

678 (Cat-1 AO project 697).

679

680

\section{REFERENCES}

682 Food and Agriculture Organization of the United Nations, "General status of the system of food 683 and agriculture statistics in Viet Nam", $\underline{\text { http://www.faorap- }}$ apcas.org/vietnam/No2_VNM 1.pdf 
685 United Nations Department of Economic and Social Affairs, Population Division, "World population

to $2300 "$, http://www.un.org/esa/population/publications/longrange2/WorldPop2300final.pdf

688 General Statistics Office of Vietnam, "Structure of used land by province", http://www.gso.gov.vn/default_en.aspx?tabid=466\&idmid=3\&ItemID=6135

690 General Statistics Office of Vietnam, "Agriculture, Fishery and Fishery Statistical Data", http://www.gso.gov.vn/default_en.aspx?tabid=469\&idmid=3

692 Food and Agriculture Organization of the United Nations, "FAOSTAT", $693 \quad$ http://faostat.fao.org/site/567/default.aspx

694 Bouvet, A., Le Toan, T., Floury, N., \& Macklin, T. (2010). An end-to-end error model for classification methods based on temporal change or polarization ratio of SAR intensities. IEEE Transactions on Geoscience and Remote Sensing, 48, 3521-3538

697 Bouvet, A., Le Toan, T., \& Lam Dao, N. (2009). Monitoring of the Rice Cropping System in the Mekong Delta Using ENVISAT/ASAR Dual Polarisation Data. IEEE Transactions on Geoscience and Remote Sensing, 47, 517-526

700 Chakraborty, M., Manjunath, K.R., Panigrahy, S., Kundu, N., \& Parihar, J.S. (2005). Rice crop parameter retrieval using multi-temporal, multi-incidence angle Radarsat SAR data.

703 Chen, C., \& McNairn, H. (2006). A neural network integrated approach for rice crop 704 monitoring. International Journal of Remote Sensing, 27, 1367-1393

Chen, J., Lin, H., \& Pei, Z. (2007). Application of ENVISAT ASAR data in mapping rice crop growth in Southern China. IEEE Geoscience and Remote Sensing Letters, 4, 431-435 
707 Frolking, S., Qiu, J., Boles, S., Xiao, X., Liu, J., Zhuang, Y., Li, C., \& Qin, X. (2002).

708 Combining remote sensing and ground census data to develop new maps of the 709 distribution of rice agriculture in China. Global Biogeochemical Cycles, 16

710 Inoue, Y., Kurosu, T., Maeno, H., Uratsuka, S., Kozu, T., Dabrowska-Zielinska, K., \& Qi, J. 711 (2002). Season-long daily measurements of mulitifrequency ( $\mathrm{Ka}, \mathrm{Ku}, \mathrm{X}, \mathrm{C}$, and L) and 712 full-polarization backscatter signatures over paddy rice field and their relationship with 713 biological variables. Remote Sensing of Environment, 81, 194-204

714 Kurosu, T., Fujita, M., \& Chiba, K. (1995). Monitoring of rice crop growth from space using the 715 ERS-1 C-band SAR. IEEE Transactions on Geoscience and Remote Sensing, 33, 1092$716 \quad 1096$

717 Le Toan, T., Laur, H., Mougin, E., \& Lopes, A. (1989). Multitemporal and dual-polarization 718 observations of agricultural vegetation covers by X-band SAR images. IEEE 719 Transactions on Geoscience and Remote Sensing, 27, 709-718

720 Le Toan, T., Ribbes, F., Wang, L.-F., Floury, N., Ding, K.-H., Kong, J.A., Fujita, M., \& Kurosu, 721 T. (1997). Rice crop mapping and monitoring using ERS-1 data based on experiment and 722 modelling results. IEEE Transactions on Geoscience and Remote Sensing, 35, 41-56

723 Liew, S.C., Kam, S.-P., Tuong, T.-P., Chen, P., Minh, V.Q., \& Lim, H. (1998). Application of 724 multitemporal ERS-2 synthetic aperture radar in delineating rice cropping systems in the 725 Mekong River Delta, Vietnam. IEEE Transactions on Geoscience and Remote Sensing, $726 \quad 36,1412-1420$

727 Lopes, A., Touzi, R., \& Nezry, E. (1990). Adaptive speckle filters and scene heterogeneity. 728 IEEE Geoscience and Remote Sensing Letters, 28, 992-1000 
729 Lopez-Sanchez, J.M., Ballester-Berman, J.D., \& Hajnsek, I. (2010). First results of rice monitoring practices in Spain by means of time series of TerraSAR-X dual-pol images. IEEE Journal of Selected Topics in Applied Earth Observations and Remote Sensing, in

Ribbes, F., \& Le Toan, T. (1999). Rice field mapping and monitoring with RADARSAT data. press International Journal of Remote Sensing, 20, 745-765

Rignot, E., \& van Zyl, J. (1993). Change detection techniques for ERS-1 SAR data. IEEE Transactions on Geoscience and Remote Sensing, 31, 896-906

Rosenqvist, A. (1999). Temporal and spatial characteristics of irrigated rice in JERS-1 L-band SAR data. International Journal of Remote Sensing, 20, 1567-1587

Sakamoto, T., Nguyen, N.V., Ohno, H., Ishitsuka, N., \& Yokozawa, M. (2006). Spatio-temporal distribution of rice phenology and cropping systems in the Mekong Delta with special reference to the seasonal water flow of the Mekong and Bassac rivers. Remote Sensing of Environment, 100, 1-16

Shao, Y., Fan, X., Liu, H., Xiao, J., Ross, S., Brisco, B., Brown, R., \& Staples, G. (2001). Rice monitoring and production estimation using multitemporal RADARSAT. Remote Sensing of Environment, 76, 310-325

Tanaka, K. (1995). Transformation of rice-based cropping patterns in the Mekong Delta: From intensification to diversification. Southeast Asian Studies, 33, 363-378

Viovy, N., Arino, O., \& Belward, A. (1992). The Best Index Slope Extraction ( BISE): A method for reducing noise in NDVI time-series. International Journal of Remote Sensing, 13, 1585-1590 
751 Wang, L.-F., Kong, J.A., Ding, K.-H., Le Toan, T., Ribbes-Baillarin, F., \& Floury, N. (2005).

752 Electromagnetic scattering model for rice canopy based on Monte Carlo simulation.

$753 \quad$ Progress In Electromagnetics Research, 153-171

754 Xiao, X., Boles, S., Frolking, S., Li, C., Babu, J.Y., Salas, W., \& Moore III, B. (2006). Mapping

755 paddy rice agriculture in South and Southeast Asia using multi-temporal MODIS images.

756 Remote Sensing of Environment, 100, 95-113

757 Xiao, X., Boles, S., Frolking, S., Salas, W., Moore III, B., \& Li, C. (2002a). Observation of 758 flooding and rice transplanting of paddy rice fields at the site to landscape scales in 759 China using VEGETATION sensor data. International Journal of Remote Sensing, 23, $760 \quad 3009-3022$

761 Xiao, X., Boles, S., Frolking, S., Salas, W., Moore III, B., Li, C., He, L., \& Zhao, R. (2002b). 762 Landscape-scale characterization of cropland in China using Vegetation and Landsat TM 763 images. International Journal of Remote Sensing, 23, 3579-3594

764 Xiao, X., Boles, S., Liu, J., Zhuang, D., Frolking, S., Li, C., Salas, W., \& Moore III, B. (2005). 765 Mapping paddy rice agriculture in southern China using multi-temporal MODIS images. 766 Remote Sensing of Environment, 95, 480-492 